\title{
Formação Profissional Integrada ao Ensino Médio: um estudo de caso com estudante surdo
}

\author{
Vocational Education Integrated to High School: a case study with a deaf \\ student
}
Formación Profesional Integrada a la Enseñanza Secundaria: un estudio de caso con estudiante sordo

\author{
Marimar da Silva \\ Professora doutora no Instituto Federal de Santa Catarina, Florianópolis, Santa Catarina, Brasil. \\ marimar.silva@ifsc.edu.br \\ ORCID - https://orcid.org/0000-0002-3132-1355 \\ Hagar de Lara Tiburcio de Oliveira \\ Professora no Instituto Federal de Santa Catarina, Gaspar, Santa Catarina, Brasil. \\ hagar.lara@ifsc.edu.br \\ ORCID - https://orcid.org/0000-0003-2019-3797
}

Recebido em 12 de agosto 2019

Aprovado em 7 de janeiro de 2020

Publicado em 9 de março de 2020

\section{RESUMO}

Este estudo, inserido na Área de Ensino, na linha de pesquisa Práticas Educativas em Educação Profissional e Tecnológica e de natureza aplicada, foi idealizado a partir da demanda de práticas educacionais inclusivas para estudantes Surdos de Cursos Técnicos Integrados ao Ensino Médio de um Instituto Federal da região sul do Brasil, e tem como objetivo compreender como o estudante Surdo aprende um conceito complexo. Para isso, foi elaborado, implementado e avaliado um produto educacional com atividades de ensino sobre o conceito de Matriz, priorizando as particularidades de aprender desse estudante. A pesquisa, um estudo de caso com um único estudante Surdo do Curso Técnico em Informática, gerou dados a partir do estudo de documentos institucionais e textos de base de dados, de entrevistas, de atividades de aprendizagem e de procedimentos metodológicos de ensino a partir de um tema gerador. A análise dos dados indica que se forem adotados regularmente procedimentos metodológicos de ensino que respeitem as especificidades de aprender do estudante surdo, agregado a recursos educacionais inclusivos, este terá mais condições de êxito na aquisição de conceitos complexos quando inseridos em contextos de ensino não-bilíngue. No entanto, o estudo alerta sobre a necessidade de expandir o universo da pesquisa visando corroborar, refutar e/ou aprofundar os resultados aqui apresentados.

Palavras-chave: Inclusão; Estudantes surdos; Formação profissional.

\section{ABSTRACT}

This study, inserted in the Teaching Area, in the Educational Practices in Vocational Education research theme, and of applied nature, was conceived from the demand of inclusive educational practices for deaf students enrolled in Integrated High School 
Vocational Program at a Federal Institute in the southeast of Brazil, and aims at understanding how a deaf student learns a complex concept. To do so, an educational product was elaborated, implemented and evaluated focusing on teaching activities about the concept of Matrix, prioritizing the participant's learning specificities. The research, a case study with only one participant enrolled in the Vocational Computing Program, generated data from the study of institutional documents and texts from database, interviews, learning activities and teaching procedures from a guiding theme. Data analysis indicates that if methodological teaching procedures are regularly adopted with a view to respecting the learning specificities of deaf students, added to inclusive educational resources, they will have more opportunities to learn complex concepts when inserted in non-bilingual educational contexts. However, the study warns about the need to expand the number of participants in order to corroborate, refute and/or enlarge the results of the present study.

Keywords: Inclusion; Deaf students; Vocational education.

\section{RESUMEN}

Este estudio, insertado en el Área de Enseñanza, en la línea de investigación Prácticas educativas en educación vocacional, y de naturaleza aplicada, fue concebido a partir de la demanda de prácticas educativas inclusivas para estudiantes sordos de cursos técnicos integrados de la escuela secundaria en un Instituto Federal de la región sur del Brasil, y tiene como objetivo comprender cómo el estudiante sordo aprende un concepto complejo. Para eso, se elaboró, implementó y evaluó un producto educativo con actividades de enseñanza sobre el concepto de Matrix, priorizando las particularidades del aprendizaje de este estudiante. La investigación, un estudio de caso con uno participante, generó datos a partir del estudio de documentos institucionales y textos de bases de datos, entrevistas, actividades de aprendizaje y procedimientos de enseñanza a partir de un tema generador. El análisis indica que si fueran adoptados regularmente procedimientos metodológicos de enseñanza que respeten las especificidades de aprender del estudiante sordo, agregado al uso de recursos educacionales inclusivos, este tendrá más oportunidades de éxito en la adquisición de conceptos complejos cuando inseridos en contextos de enseñanza non-bilingüe. Entretanto, el estudio alerta para la necesidad de ampliar el universo de participantes para corroborar, refutar y/o ampliar los resultados aquí presentados.

Palabras clave: Inclusión; Estudiantes sordos; Formación profesional.

\section{Introdução}

Embora historicamente (e depois de muitas lutas) a Comunidade Surda brasileira tenha conquistado politicamente o direito de ter uma língua legítima: Libras, por meio da Lei 10.436/02, ainda há políticas de inclusão no âmbito da Educação Especial que perpetuam práticas de natureza discriminatória, provavelmente embasadas na concepção clínica da surdez, que não respeita as especificidades de aprendizagem do estudante Surdo ${ }^{1}$ (SKLIAR, 2016), tratando-o como deficiente em vez de diferente, excluindo-o em vez de incluí-lo. 
http://dx.doi.org/10.5902/1984686X39507

Este artigo, um recorte de uma pesquisa de Mestrado Profissional em Educação Profissional e Tecnológica em Rede Nacional//FSC ${ }^{2}$, alinhado aos estudos de Lacerda, Santos, Caetano (2014), Figueiredo (2015), e Skliar (2016), entre outros, parte da premissa de que se respeitadas as especificidades de aprender do estudante Surdo, este terá mais condições de aprender conceitos, sejam complexos ou simples, e, portanto, mais condições e oportunidades de inserção no mundo do trabalho.

O presente artigo, um estudo de caso com um estudante Surdo do Curso Técnico em Informática Integrado ao Ensino Médio, de um Instituto Federal da região sul do Brasil, e com abordagem qualitativa dos dados, buscou demonstrar que o participante, um sujeito com nível de surdez severo ${ }^{3}$ e conhecimento reduzido de Libras $\left(L 1^{4}\right)$ e de português escrito $\left(\mathrm{L}^{5}\right)$, é capaz de aprender conceitos complexos se respeitada a forma como aprende e interage com o mundo ao seu redor. Para isso, foi desenvolvido um Produto Educacional, no formato de sequência de atividades de ensino intitulada: Aprendendo para ensinar matrizes: atividades de ensino de estudante Surdo para estudante Surdo na EPT, com atividades de aprendizagem e procedimentos metodológicos, respeitando a forma visoespacial de aprender e interagir socialmente do estudante Surdo.

Com este estudo pretende-se contribuir para as pesquisas na área de ensino inclusivo, promover igualdade de oportunidades e condições de acesso ao conhecimento formal ao estudante Surdo, além de sugerir alternativas para que professores de instituições de ensino não-bilíngue possam ressignificar suas práticas, quebrando, quem sabe, um ciclo vicioso que pretende incluir, mas que, na verdade, exclui por partir de uma concepção discriminatória sobre o sujeito Surdo ou por desconhecer a forma como este aprende e interage socialmente.

Este artigo está organizado em cinco seções. A primeira apresentou brevemente a pesquisa, a segunda traz os referenciais teóricos do estudo, a terceira aborda seu percurso metodológico, a quarta descreve e analisa a implementação do produto educacional, e a quinta traz as considerações finais do estudo.

\section{Compreensões sobre a Surdez e a EPT: tema e foco do estudo}

Os estudos culturais buscam "investigar a cultura em seu contexto histórico, utilizando novos métodos etnometodológicos de pesquisa, empregando uma abordagem 
http://dx.doi.org/10.5902/1984686X39507

hermenêutica às questões do significado". (SÁ, 2010, p. 52). A surdez, sob o ponto de vista dos estudos culturais, é compreendida como uma questão de diferença política, de experiência visual, sem referência à patologia (ausência total ou parcial da percepção do som pelo sujeito) ou deficiência, como entende a perspectiva médica.

Assim, na perspectiva dos estudos culturais, os Surdos são vistos como diferentes, integrantes de uma comunidade com cultura e língua próprias. Nesse sentido, Sá (2010) propõe que os estudos dessa natureza sobre a temática da surdez desenvolvam pesquisas a partir de uma abordagem crítica do sujeito Surdo, valorizando sua cultura. É a partir dessa concepção de surdez e de sujeito Surdo que este estudo se estrutura.

Alinhado a essas compreensões, Skliar (2016, p.11), em sua obra "Os Estudos Surdos em Educação: problematizando a normalidade”, caracteriza a surdez como: "[...] uma diferença a ser politicamente reconhecida; [...] uma experiência visual; [...] uma identidade múltipla ou multifacetada [...] localizada dentro do discurso sobre a deficiência". Já o Decreto 5.626, de 2005, agrega a essa temática a forma como o sujeito Surdo interage socialmente com o meio: "por ter perda auditiva, [o Surdo] compreende e interage com o mundo por meio de experiências visuais, manifestando sua cultura principalmente pelo uso da Libras". (BRASIL, 2005, n.p.).

A partir dessas contribuições sobre a temática da surdez e do sujeito Surdo, pode-se inferir que a limitação auditiva desses sujeitos não os impede de compreender e interagir plenamente com o contexto onde vivem e/ou trabalham, desde que lhes sejam viabilizadas as condições necessárias. Estendendo essa compreensão para 0 contexto educacional não-bilíngue, contexto do presente estudo, pode-se igualmente inferir que, para que estudantes Surdos possam se apropriar do conhecimento formal para poderem competir em igualdade de condições e oportunidades no mundo do trabalho, deve-se entendê-los como membros de uma comunidade específica, com cultura e idioma próprios, e que aprendem a partir de experiências visuais.

Embora a comunidade Surda defenda uma escola bilíngue ${ }^{6}$ para Surdos, o Brasil ainda está aquém do que essa comunidade deseja. O que a legislação brasileira atualmente oferece é uma política de educação especial na perspectiva inclusiva. Em outras palavras, o estudante Surdo é inserido em classes regulares com estudantes ouvintes, em instituições de ensino não-bilíngues, assistido por um profissional intérprete de Libras e por profissionais de atendimento educacional especializado (AEE) na sua primeira língua (L1/Libras) e segunda língua (L2/português escrito). Por força de lei, essas 
http://dx.doi.org/10.5902/1984686X39507

condições básicas são ofertadas aos estudantes Surdos, tanto da educação básica regular quanto da Educação Profissional e Tecnológica (EPT doravante), modalidade de ensino que também tem suas especificidades.

A educação técnica integrada na modalidade de ensino médio, por exemplo, pode ser concebida como a integração da educação básica com os eixos estruturantes da ciência, da tecnologia, da cultura e do trabalho, e organizada de forma tal que o estudante tem acesso ao currículo formal do ensino médio, isto é, o propedêutico, atrelado ao currículo técnico do curso escolhido para a formação para o mundo do trabalho.

Para Machado (2010), a integração do ensino médio com o ensino técnico concretizou-se a partir do Decreto 5.154/04. Antes disso, a formação para o trabalho e a formação propedêutica eram tidas de forma independente. O decreto menciona que 0 ensino médio articulado com a educação técnica dar-se-á:

[...] de forma integrada, oferecida somente a quem já tenha concluído o ensino fundamental, sendo o curso planejado de modo a conduzir o aluno à habilitação profissional técnica de nível médio, na mesma instituição de ensino, contando com matrícula única para cada aluno. (BRASIL, 2004, n.p.).

Ou seja, o estudante, com uma única matrícula, será contemplado com a formação profissional concomitante à conclusão do ensino médio, última etapa da educação básica. É nessa modalidade de ensino que o presente estudo se insere.

Em relação à EPT, Ramos (2010) alerta que a integração do ensino médio ao ensino técnico não é simplesmente a soma das disciplinas da educação básica com as da formação técnica, tampouco a soma de cargas horárias, mas trata-se da mediação do trabalho, a produção do conhecimento científico e da cultura por meio da "organização curricular e do desenvolvimento do processo de ensino-aprendizagem, conhecimentos gerais e específicos; cultura e trabalho; humanismo e tecnologia." (RAMOS, 2010, p. 52).

Ainda, segundo Ciavatta (2005), Ramos (2010), Machado (2010), Araújo e Frigotto (2015), o currículo integrado pode ser conceituado como o ato de reconhecer o estudante como um ser em constante transformação, um sujeito sociohistórico, e que pressupõe o trabalho como princípio educativo, visando à emancipação, à superação da dominação dos trabalhadores e à formação de um cidadão transformador da sociedade. Além disso, o currículo integrado pressupõe propostas de ação didáticas contextualizadas, focadas na ampliação da capacidade das pessoas de compreenderem a sua realidade específica e a 
http://dx.doi.org/10.5902/1984686X39507

relação desta com a totalidade social, usando a tecnologia (ou ciência da atividade humana) como prática social.

Uma prática integradora, segundo Araújo e Frigotto (2015, p. 66), requer "uma atitude docente integradora, orientada pela ideia de práxis", promovendo a integração de [...] "saberes e práticas locais com os saberes e práticas globais" [...]. Sobre essa questão, Ciavatta (2005) assevera que:

[...] a formação integrada entre o ensino geral e a educação profissional ou técnica [...] exige que se busquem os alicerces do pensamento e da produção da vida além das práticas de educação profissional e das teorias da educação propedêutica que treinam para o vestibular. Ambas são práticas operacionais e mecanicistas e não de formação humana no seu sentido pleno. (CIAVATTA, 2005, p. 10)

Contribuindo para essa linha de argumentação, Machado (2010) coloca que uma prática integradora pressupõe explorar os diversos contextos em que os educandos estão inseridos e as práticas que ajudam a construir o trabalho interdisciplinar.

Alinhado aos autores aqui apresentados, este estudo considera a interdisciplinaridade uma prática essencial no contexto do ensino médio integrado, já que pressupõe uma preparação para o mundo do trabalho. Uma docência fragmentada entre formação técnica e formação propedêutica, além de não ser a base epistemológica de um currículo integrado, prejudica o estudante no sentido de aumentar a carga de conteúdos descontextualizados para sua formação.

Além disso, com vistas à superação da dicotomia trabalho manual versus trabalho intelectual, Ciavatta (2005) defende que:

No caso da formação integrada ou do ensino médio integrado ao ensino técnico, queremos que a educação geral se torne parte inseparável da educação profissional em todos os campos onde se dá a preparação para o trabalho: seja nos processos produtivos, seja nos processos educativos como a formação inicial, como o ensino técnico, tecnológico ou superior (CIAVATTA, 2005, p. 84).

Pensando numa perspectiva de inclusão, a prática docente de formação geral unida à prática de formação técnica auxilia o estudante a assimilar conceitos mais facilmente e contribui para diminuir a carga conteudista, dando mais tempo e significado à aprendizagem.

As estratégias docentes sugeridas por Araújo e Frigotto (2015) para essa integração são: o trabalho mediante projetos integradores por meio de uma pedagogia de base social 
http://dx.doi.org/10.5902/1984686X39507

que valorize e promova a autonomia do estudante e o trabalho colaborativo como estratégia de trabalho pedagógico. Os autores ainda sugerem como estratégias didáticas:

\begin{abstract}
Aulas expositivas, estudo do meio, jogos didáticos, visitas técnicas Integradas, seminários, estudo dirigido, oficinas e várias outras estratégias de ensino e aprendizado podem servir tanto para projetos conservadores, tradicionais, conformadores das capacidades humanas, quanto para projetos libertários, comprometidos com a ampliação das capacidades humanas. (ARAÚJO; FRIGOTTO, 2015, p. 76).
\end{abstract}

Pensar essa práxis num contexto de educação profissional requer formação continuada dos professores, já que, segundo dados de Lima (2014) e da Plataforma Nilo Peçanha (plataforma estatística para análise de dados e indicadores da Rede Federal de Educação Profissional, Cientifica e Tecnológica do Brasil), na realidade educacional vigente, são poucos os profissionais dos Institutos Federais (IF) que têm formação específica para trabalhar com a Educação Profissional. Numa tentativa de preencher essa lacuna, a Resolução 06 de 20 de setembro de 2012 estabelece que os(as) profissionais atuantes nos IF têm até 2020 para se adequarem.

No tocante à inclusão, a resolução ainda traz, entre outros princípios norteadores, a seguinte redação no Art. 6º, parágrafo 10:

[...] o reconhecimento dos sujeitos e suas diversidades, considerando, entre outras, as pessoas com deficiência, transtornos globais do desenvolvimento e altas habilidades, as pessoas em regime de acolhimento ou internação e em regime de privação de liberdade [...] (BRASIL, 2012, n.p.).

Tendo em vista o reconhecimento da diversidade dos sujeitos nos espaços educativos da EPT, cabe considerar, na próxima seção, as formas de aprender desses sujeitos a partir de alguns conceitos desenvolvidos por Vygotsky ${ }^{7}$ e de pesquisas conduzidas na área deste estudo.

\title{
Conceitos Vygotskyanos e Estudos Sobre o Desenvolvimento do Estudante Surdo: aprofundando o tema da pesquisa
}

Vygotsky (1989) trouxe amplas contribuições aos estudos acerca da linguagem e do desenvolvimento, estudando as funções psicológicas superiores nas crianças. Além disso, colaborou com teorias sobre a criança com deficiência, concentrando "sua atenção nas habilidades que tais crianças possuíam, habilidades estas que poderiam formar a base para o desenvolvimento de suas capacidades integrais." (VYGOTSKY; LURIA; LEONTIEV, 1988, p. 34). 
http://dx.doi.org/10.5902/1984686X39507

Em seus estudos, o conceito de mediação proposto por Vygotsky (1989) é vital para o desenvolvimento cognitivo/aprendizagem de um sujeito. Segundo Oliveira (1997, p. 26), "mediação, em termos genéricos, é o processo de intervenção de um elemento intermediário numa relação; a relação deixa, então, de ser direta e passa a ser mediada por esse elemento". A mediação também é vital para a aprendizagem da linguagem e para a formação da Zona de Desenvolvimento Proximal (ZDP), definida por Vygotsky como a distância entre aquilo que o sujeito consegue fazer com auxílio e o que faz sozinho. (OLIVEIRA, 1997).

Ainda, as ações dos sujeitos são reguladas pela linguagem. Conforme destacam Vygotsky, Luria e Leontiev (1988),

[...] é com base na linguagem que se formam complexos processos de regulação das próprias ações do homem [...] embora, no início, a linguagem seja uma forma de comunicação entre o adulto e a criança, a linguagem vai assim gradualmente se transformando em uma forma de organização da atividade psicológica humana. (VYGOTSKY, LURIA, LEONTIEV, 1988, p. 197).

Em seus estudos, Vygotsky (1989) afirma que a relação da criança com o mundo é uma relação mediada por ferramentas auxiliares da atividade humana: os instrumentos e os signos, compreendido, este último, como representações mentais que dão significado a algo, como fazer uma amarração no dedo para lembrar de algo, por exemplo. (OLIVEIRA, 1997). A autora ainda considera que:

[...] a invenção e o uso de signos como meios auxiliares para solucionar um dado problema psicológico (lembrar, comparar coisas, relatar, escolher, etc.), é análoga à invenção e uso de instrumentos, só que agora no campo psicológico. O signo age como um instrumento da atividade psicológica de maneira análoga ao papel de um instrumento no trabalho. (OLIVEIRA, 1997, p. 30)

Além disso, é por meio da mediação de instrumentos que se dá a linguagem, e é por meio dela que ocorre a aprendizagem, segundo Vygotsky (1989). Em outras palavras, a linguagem está imbricada na aprendizagem. Nessa perspectiva, o autor considera que:

[...] o momento de maior significado no curso do desenvolvimento intelectual, que dá origem às formas puramente humanas de inteligência prática e abstrata, acontece quando a fala e a atividade prática, então duas linhas completamente independente de desenvolvimento, convergem. (VYGOTSKY, 1989, p. 27)

Ou seja, o teórico assume que a fala guia a atividade humana e, posteriormente, essa comunicação consigo mesmo fica tão internalizada que o sujeito se utiliza disso para 
http://dx.doi.org/10.5902/1984686X39507

guiar sua aprendizagem. Considerando o sujeito Surdo, por mais que não tenha a fala oralizada, ele fala consigo mesmo por meio de imagens ou sinais que aprendeu com a mediação social. Em outras palavras, a criança Surda, mesmo quando ainda desprovida de linguagem, seja oral ou de sinais, aprende observando e vendo, diferentemente da criança ouvinte, que aprende ouvindo.

Sobre essa temática, Damásio (2000, apud SANTANA, 2007) afirma que, por meio de estímulos e novas experiências, o design dos circuitos cerebrais se modificam. Em sendo assim, caso não haja estimulação por uma equipe interdisciplinar, a pessoa Surda pode ficar com um déficit intelectual irreversível, uma vez que não consegue interagir com o ambiente em que está inserida (SANTANA, 2007). Nesse cenário, pode-se inferir que a estimulação precoce da linguagem na criança, e aqui inclui-se a Surda também, é fundamental na/para a aquisição de conhecimento.

Contribuindo para essa temática, o estudo de Santana (2007) ainda argumenta que, ao se viabilizar à pessoa surda o acesso aos serviços de aprendizagem e acompanhamento cognitivo com uma equipe capacitada é possível que ela tenha avanços significativos, tanto na aquisição da linguagem como em outras aprendizagens, confirmando, assim, a plasticidade cerebral. Nesse sentido, a Comunidade Surda defende que, no caso de filhos Surdos de pais ouvintes, é fundamental que eles interajam socialmente com crianças e adultos Surdos para, assim, adquirirem a Língua de Sinais.

Com base na discussão aqui feita, no caso de pessoas Surdas, os instrumentos de mediação de desenvolvimento cognitivo/aprendizagem são, além dos profissionais envolvidos em sua estimulação, as ferramentas que utilizam para possibilitar aprendizagem, isto é, o uso de objetos e signos que lhes são apresentados uma vez que compreendem de forma visual.

A título de exemplificação, os programas ofertados pela TV INES são programas voltados para o desenvolvimento cognitivo e a aprendizagem do sujeito Surdo, que usam objetos e signos a partir de uma perspectiva visual bilíngue: Libras e português escrito, proporcionando aos que os acessam uma interação com a Cultura e a Comunidade Surda, conforme defendem Figueiredo (2015), Quadros e Schmiedt (2006), Siqueira (2018), entre outros.

Agrega-se a essa discussão o fato de que é basilar o educador ter conhecimento sobre os aspectos da surdez, bem como um olhar aguçado sobre as peculiaridades do sujeito Surdo, para que esse profissional assuma uma postura inclusiva no ato de ensinar. 
http://dx.doi.org/10.5902/1984686X39507

Entre essas posturas podemos citar: sempre dirigir-se ao estudante Surdo e não ao intérprete quando for explicar algo, tocá-lo no braço ao falar com ele, além de buscar informações sobre quem ele é, de onde vem e o que espera da instituição, dentre outras atitudes que podem contribuir para que este se sinta respeitado e perceba que o professor tem iniciativas inclusivas. Dessa forma, abre-se espaço para a construção de uma relação afetiva entre professor e estudante, que contribui para o processo de aprendizagem e pode dar pistas de como o professor pode desenvolver práticas pedagógicas diferenciadas.

Sobre o ensino de língua portuguesa como L2 para alunos Surdos em fase de alfabetização, por exemplo, o estudo de Oliveira e Schmitt (2016) defende que tanto os instrumentos quanto os signos utilizados pelo professor devem ser visuais. Em outras palavras, o docente deve fazer uso de imagens do que será ensinado, o sinal em Libras, a palavra impressa e, depois, a soletração.

Contribuindo para a discussão sobre a educação de alunos Surdos, Quadros e Schmiedt (2006); Salles, et al. (2007) advertem para a importância de valorizar a Cultura Surda e as produções dos alunos Surdos como fundamentação para o ensino da L2, já que a Libras é a sua primeira língua, portanto merece reconhecimento. Segundo Quadros e Schmiedt (2006, p. 25), “[o] que os alunos produzem hoje espontaneamente, pode se transformar em fonte de inspiração literária dos alunos de amanhã. O que os professores relatam hoje, podem ser aperfeiçoados no dia de amanhã".

Já em relação ao ensino de matemática, considerando as especificidades do estudante Surdo, Rezende (2017) argumenta que é imprescindível oportunizar uma experiência visual para esse público. Conforme defende o autor, "é importante pensar no ensino de matemática que permita ao aluno 'ver com as mãos', no sentido de tocar, sentir, movimentar e manipular, com o intuito de compreender conceitos matemáticos". (REZENDE, 2017, p.67-68). Essa abordagem de ensino de matemática propicia um contato visual com o material, que facilita a compreensão não apenas de estudantes Surdos, mas também de ouvintes.

Considerando as especificidades da EPT apresentadas nesta seção; considerando ainda que, segundo Vygotsky (1989), os processos internos de desenvolvimento são acionados quando há interação e cooperação com pessoas em um dado ambiente, que a escrita seja ensinada na perspectiva de seu uso social, não mecanicamente ou descontextualizada; considerando também que, segundo a legislação brasileira, "a Libras 
http://dx.doi.org/10.5902/1984686X39507

não poderá substituir a modalidade escrita da língua portuguesa" (BRASIL, 2002), e que o ensino de português para estudantes Surdos deve ser na modalidade escrita, este estudo busca compreender como o estudante Surdo aprende conceitos complexos a partir de uma abordagem de ensino interdisciplinar entre a área de matemática, informática e linguagem: Libras e português escrito, por meio do desenvolvimento e implementação de um produto educacional. O método que guiou o estudo é apresentado na próxima seção.

\section{Percurso Metodológico do Estudo}

A pesquisa ${ }^{8}$, um estudo de caso (YIN, 2015) com um estudante Surdo do Curso Técnico em Informática Integrado ao Ensino Médio, de um Instituto Federal da região sul do Brasil, e com abordagem qualitativa dos dados (PRODANOV; FREITAS, 2013), buscou demonstrar que o participante, um sujeito com nível de surdez severo e conhecimento reduzido de Libras (L1) e de português escrito (L2), é capaz de aprender conceitos complexos desde que respeitada a forma como aprende e interage com 0 mundo ao seu redor. Guiou o estudo a seguinte pergunta de pesquisa: Como ensinar conceitos complexos a estudantes Surdos para que tenham acesso ao conhecimento formal no contexto de formação profissional integrado ao ensino médio e mais condições e oportunidades de inserção no mundo do trabalho?

Os dados foram gerados a partir do estudo de documentos institucionais e de textos da base de dados da CAPES e de periódicos, de entrevistas com os pais do participante, de questionários de avaliação (LAKATOS; MARCONI, 2003) aplicados ao estudante e ao intérprete de Libras ao final de cada fase do processo de intervenção, e dos dados gerados do produto educacional desenhado para o estudo: atividades de ensino a partir do tema gerador - conceito e uso de Matriz - que foram abordadas de forma interdisciplinar nos planos de aula, cujas aulas foram videogravadas para análise posterior. Ainda sobre o tema do produto educacional, este foi sugerido pela professora de matemática do curso técnico em informática no qual o participante da pesquisa estava matriculado, tendo em vista ser um conceito fundamental para o seu componente curricular no momento da pesquisa, assim como para o de programação. Além do mais, o estudo de Zwan (2016) sinaliza que Matriz é um conteúdo difícil para estudantes Surdos aprenderem.

Assim, o produto educacional, desenhado a partir da literatura revisada para o estudo, foi organizado em três fases sequenciais: i) fase diagnóstica, visando identificar o 
nível de desenvolvimento real/conhecimento (VYGOTSKY, 1989) do participante sobre o conceito e uso de Matriz na informática, área de formação profissional do participante; ii) fase de intervenção, visando ampliar o nível de desenvolvimento/conhecimento identificado na primeira fase do estudo (AUSUBEL, 2000 apud MOREIRA, 2010), a partir de atividades de aprendizagem e de procedimentos metodológicos voltados à forma de aprender do participante (LACERDA; SANTOS; CAETANO, 2014; FIGUEIREDO, 2015; SKLIAR, 2016); e iii) fase de produção de videoaula pelo próprio participante sobre o conceito e uso de Matrix para outros estudantes Surdos, visando identificar o nível de desenvolvimento/conhecimento alcançado pelo participante ao final do processo.

As diferentes fases, por sua vez, foram organizadas no formato de planos de aula ${ }^{9}$, cujos elementos foram descritos minuciosamente ${ }^{10}$. Ou seja, o conteúdo das aulas; os objetivos de aprendizagem; os procedimentos metodológicos que buscaram levar 0 participante a alcançar os objetivos; as atividades de aprendizagem e seus respectivos gabaritos; os recursos didáticos; as tarefas de casa, com características semelhantes às usadas em aula, mas com desafios crescentes e formatos diversificados; e a forma de avaliação das aulas foram todos, obrigatoriamente, pensados para as especificidades de aprender do participante.

Por fim, mas não menos importante, os planos de aula traziam um questionário de avaliação da aula, a ser respondido a partir da perspectiva do participante e do intérprete, buscando identificar os pontos positivos e as fragilidades das aulas, para que a aprendizagem fluísse de forma gradual nas aulas subsequentes. Agregou-se ainda ao questionário de avaliação o registro das percepções do pesquisador sobre as aulas em seu diário de bordo (BOGDAN; BIKLEN, 1994), que foram somados aos dados gerados.

Para a análise dos dados gerados, o método escolhido foi de cunho qualitativo, com o uso da Análise de Conteúdo para a categorização e o tratamento dos dados, definida por Bardin (1977) como um método de pesquisa para descrever e interpretar conteúdos de documentos e textos, auxiliando na reinterpretação dos discursos e na compreensão de seus significados, que são apresentados na próxima seção.

\section{Análise e Discussão dos Dados}

Como mencionado anteriormente, o produto educacional proposto para confirmar ou refutar a premissa que embasa o presente estudo e responder a pergunta de pesquisa foi desenvolvido em três fases com objetivos específicos. $\mathrm{Na}$ fase de diagnóstico, as 
http://dx.doi.org/10.5902/1984686X39507

atividades, organizadas em dois momentos, buscaram identificar 0 nível de desenvolvimento real (VYGOTSKY, 1989) ou o conhecimento prévio (FREIRE, 1996) do participante sobre o conceito e uso de Matriz no momento da pesquisa, além do conhecimento e uso de aplicativos e mídias digitais, pois seriam usados ao longo do processo de intervenção. Ainda, as atividades propostas para essa fase e as posteriores, assim como os procedimentos metodológicos, foram mediados por adultos experientes (VYGOTSKY, 1989), ou seja, pesquisador e intérprete de Libras do câmpus, por recursos imagéticos concretos, impressos e digitais (FIGUEIREDO, 2015), além da Libras e do português escrito, primeira e segunda língua do participante, respectivamente.

Nessa fase, a análise dos dados do questionário indicou que o participante usava mídias e aplicativos apenas para lazer, como mostra o excerto 1 traduzido para Libras e para o português pelo intérprete.

\section{Excerto 1:}

Pesquisadora: Você costuma assistir vídeos?

Estudante: - Um pouco, às vezes. Mas assim, não olho todo dia, não né! Algumas vezes assim eu olho, mas não é muito não.

Pesquisadora: Que tipo de vídeos?

Estudante: - Ah... vários vídeos, eu gosto muito de... coisas de monstros, umas piadas. Algumas coisas assim, mais por diversão.

Pesquisadora: Você assiste vídeos para estudar?

Estudante: - É... Não, não. [...] eu gosto de assistir outras coisas. [Questionário, 11 Fev. 2019]

Já em relação aos conteúdos trabalhados no ensino médio, das quatro imagens referentes aos conteúdos: equação linear, determinantes, matriz e lei dos senos, o participante lembrou de ter estudado equação linear e lei dos senos, que não estão diretamente ligados ao conhecimento de matriz. E em relação ao conceito de tabela, lembrou do sinal em Libras, mas desconhecia os sinais de linha e coluna e o uso de Matriz na informática, como mostra o excerto 2.

Excerto 2:

Pesquisadora: Você sabe onde são utilizadas matrizes na área de informática? 
http://dx.doi.org/10.5902/1984686X39507

Estudante: Não tem eu acho. Acho que só na matemática. Só no papel [exercícios impressos de Matriz da aula de matemática], não sei se tem [exercícios de Matriz] no computador. [Questionário, 11 Fev. 2019]

Os achados dessa fase, no que se refere ao conteúdo Matriz estudado pelo participante no ensino médio, porém não aprendido, corroboram o estudo de Zwan (2016), que afirma que o conceito de matriz é um conceito difícil de o Surdo aprender. Já no que se refere ao uso de aplicativos e mídias digitais, o participante desconhece o potencial dessas ferramentas na aprendizagem de conceitos, temas e conteúdos educacionais, achados estes que dão subsídios à premissa colocada para o presente estudo.

Assim, a partir dos resultados da fase diagnóstica, foi planejada a intervenção, também organizada em dois momentos. O primeiro momento buscou ensinar ao participante o conceito de tabela e seus elementos: linha e coluna, pois são basilares para a compreensão do conceito de Matriz, e o segundo foi reservado à busca de exemplos do uso de Matriz na Informática, para que o participante percebesse a relação entre 0 conhecimento trabalhado em sala de aula (Matriz) e a sua aplicabilidade em diferentes atividades na vida real: elaboração da planilha excel, da mídia social Instagram, de imagens rotativas em 3D, entre outras.

Igualmente à fase anterior, os procedimentos metodológicos e as atividades de aprendizagem de ambos os momentos da fase de intervenção também foram mediados pelo pesquisador e intérprete de Libras do contexto da pesquisa, por materiais concretos (cartolina, representando uma tabela com linhas e colunas) e objetos reais (balas, chocolates, tampas de garrafa pet etc., representando os elementos da tabela), além de recursos imagéticos impressos e digitais, de computador para navegação na Internet, da Libras (L1) para a interação visoespacial com o participante e do português escrito (L2), para que este pudesse fazer a relação entre o sinal em Libras e o português escrito, ampliando seu conhecimento na L2.

No primeiro momento da intervenção, as atividades de aprendizagem, sustentadas em Vygotsky (1989), Freire (1996), Moreira (2010), Rezende (2017) e Zwan (2016), incluíram a localização de objetos manipuláveis nas linhas e colunas da tabela, a colocação de objetos conforme comando do pesquisador; exemplificação do uso de tabela para a organização das atividades escolares e profissionais; resolução de 
http://dx.doi.org/10.5902/1984686X39507

atividades com imagens dos sinais de linha, coluna e matriz em Libras e a palavra correspondente escrita em português.

Já no segundo momento, as atividades de aprendizagem estavam relacionadas ao uso de Matriz na área da informática e à ampliação do conhecimento do participante sobre plataformas digitais, que podem contribuir para o seu desenvolvimento cognitivo e autonomia para aprender. Para tanto, o participante fez buscas na internet, aprendeu algumas funções e ferramentas da plataforma Google, como o armazenamento de informações no Drive e Google Imagens para ajudá-lo na compreensão de palavras ou expressões ainda desconhecidas, já que aprende vendo e manipulando (REZENDE, 2017), e explorou os programas da TV INES e do YouTube ofertados para o público Surdo.

Cabe ressaltar que todas as atividades de aprendizagem, além de respeitarem as especificidades de aprender do participante Surdo, foram planejadas de tal forma que 0 conteúdo abordado se repetia em formato diversificado, acrescentando sempre um desafio cognitivo novo, mas calibrado ao nível de conhecimento real do participante. Dessa forma, agregando às especificidades de aprender do participante atividades de aprendizagem calibradas sobre o mesmo objetivo (aprender um conceito complexo) de forma cíclica gradativa e crescente, buscou-se criar a melhor condição de ensino possível para que o participante aprendesse o conceito e uso de Matriz, comprovadamente tido como um conceito complexo para ser aprendido pelo estudante Surdo (ZWAN, 2016).

Em outras palavras, as atividades de aprendizagem partiram do ensino do conceito de tabela, linha e coluna para o conceito de Matriz. Essa decisão deu-se pelo fato de a Matriz ser representada em tabela e seus elementos organizados em linha e coluna, e pelo fato de os conceitos de tabela, linha e coluna serem encontrados em diferentes práticas sociais, portanto mais simples de serem representados de forma concreta, que pode abrir caminho para que processos cognitivos superiores como inferência, dedução, associação, comparação (VYGOTSKY, 1989) emerjam mais facilmente, como sinaliza o excerto 3.

Excerto 3:

Pesquisadora: [buscando relacionar o conceito de tabela com a vida real] Você tem uma tabela de horário de aulas, por exemplo?

Estudante: [expressão facial de dúvida do participante]. 
http://dx.doi.org/10.5902/1984686X39507

Pesquisadora: Você não tem uma tabela de horário de aula? Segunda, você tem aula de informática, de física, de português.

Estudante: Ah, sim, primeiro é matemática, português.

Pesquisadora: Isso!

Estudante: Tem coluna, linha [na tabela de horário]...

Pesquisadora: Isso [o horário das aulas] é uma tabela, tabela de horários de aula. Eu também tenho uma tabela de horário. [Diário, 18 Fev. 2019]

Como mostra o excerto 3, o participante usou processos cognitivos superiores para entender que o quadro de horário de aula é uma tabela, que tem colunas e linhas onde são colocadas as aulas do dia, e que Matriz parte do mesmo princípio. A partir dessa compreensão, o participante conseguiu resolver atividades de aprendizagem com situações-problema sobre Matriz e obter sucesso na prova de matemática do curso.

Além do mais, percebeu-se que, devido ao fato de o participante ter conhecimento restrito na L2: "Em língua de sinais, eu consigo entender bem, mas assim, quando é em português, aí fica um pouco mais complicado". [Questionário, 11 Fev. 2019], havia necessidade de se pensar uma forma de facilitar a compreensão das atividades impressas e escritas em português para o participante. Para tanto, apenas as palavraschave dessas atividades foram marcadas em maiúscula e/ou em negrito, ressaltando a importância do que era solicitado fazer.

Ademais, foi-Ihe ensinado a usar ferramentas digitais de armazenamento de informação e comunicação, como mostra o excerto 4, além de ferramentas de busca de imagem na Internet, com atividades práticas no computador, visando levar o participante a compreender o significado das palavras-chave, conhecimento este que abre a possibilidade de dar mais autonomia ao sujeito para aprender e interagir com o meio, mediado pela palavra escrita e ferramentas digitais.

\section{Excerto 4:}

Estudante: [sobre a ferramenta de texto - Docs - do Google Drive] Parece que é para escrever texto.

Pesquisadora: Sim, também. Se você quiser, por exemplo, que outra pessoa veja um texto que você está escrevendo, você compartilha e os dois podem escrever ao mesmo tempo.

Estudante: Quero aprender a compartilhar texto. 
http://dx.doi.org/10.5902/1984686X39507

Pesquisadora: O estudante ficou entusiasmado quando viu a foto do seu rosto no canto superior direito do meu computador porque estávamos editando o mesmo documento. [Diário, 15 Mar. 2019]

Da fase de intervenção, evidenciou-se que a aprendizagem tem mais condições de ser exitosa se mediada não só pelo professor/intérprete de Libras, mas também por ferramentas tecnológicas visuais, pois facilitam uma evolução da zona de desenvolvimento proximal (VYGOTSKY, 1989). Evidenciou-se também que o uso de estratégias de repetição de atividades diversificadas e calibradas sobre um mesmo tema/conteúdo e/ou objetivo de aprendizagem, o uso de marcação de palavras-chave no português escrito, sinalizando a essência da tarefa para o estudante Surdo, e o uso da imagem simultaneamente ao uso da Libras e do português escrito, criam condições favoráveis para a aprendizagem de conceitos complexos.

Por fim, a terceira fase do produto educacional buscou identificar a eficácia do processo de intervenção realizado na fase de intervenção e avançar, em alguma medida, no desenvolvimento/aprendizagem do participante, já que propunha a produção de videoaula pelo próprio participante sobre conceito e uso de Matriz para outros estudantes Surdos.

Para tanto, propôs-se primeiramente ao participante a elaboração de um roteiro para videoaulas que ele mesmo protagonizou. Para subsidiar essa produção, foram trabalhados dois folders adaptados de Oechsler (2018), com ilustrações e palavras-chave escritas em português, para que o participante aprendesse a elaborar o roteiro para o seu vídeo.

A atividade de aprendizagem dessa fase solicitava ao participante que desenhasse os elementos do seu roteiro, tendo em vista que o desenho é mais uma estratégia que os professores podem lançar mão ao planejarem atividades para estudantes Surdos, pois materiais ilustrados construídos pelos próprios estudantes ajudam a relacionar o signo ao seu significado. Conforme Oliveira (1997, p. 30), "o signo age como um instrumento da atividade psicológica [...] sendo utilizado para lembrar, comparar coisas, relatar, escolher, etc.". Ademais, o desenho é uma importante ferramenta de demonstração de conhecimento e está alinhado à potencialidade visual dos Surdos, como preconizam Quadros (1997), Salles (2007), Sacks (2010), Lacerda, Santos e Caetano (2014), Figueiredo (2015). 
http://dx.doi.org/10.5902/1984686X39507

A partir dessas compreensões, para a elaboração do roteiro do vídeo também foram realizadas atividades voltadas para a análise de vídeos da TV INES e do YouTube, instigando o participante a perceber a diferença entre aulas para Surdo feitas por ouvintes e aulas feitas por Surdos para Surdos. A atividade focou nos recursos imagéticos de língua de sinais, nas legendas em português e nas imagens referentes à temática, já que se buscava criar condições para que o participante elaborasse seu vídeo com esses elementos.

Os resultados obtidos nessa fase sinalizam que o participante havia se apropriado não apenas do conteúdo trabalhado na fase de intervenção, mas também dos elementos para a elaboração da sua videoaula, conforme mostra o excerto 5.

\section{Excerto 5:}

Pesquisadora: Você tem ideia do que é necessário para produzir uma videoaula?

Estudante: Preciso falar [em Libras] o que é matriz; explicar cada coisa [mostrar o sinal e o português]: o que é coluna, linha, $m, n$, quantas linhas e quantas colunas; qual é o elemento correto, vários exemplos que ele [o professor do vídeo da TV INES] deu; tenho que decorar o nome e explicar. [Diário, Abr., 2019].

Foi verificado ainda que as atividades de aprendizagem voltadas para a identificação de como fazer uma aula para Surdos, a partir de tarefas de observação de aulas da TV INES e do YouTube, levaram o participante a perceber a importância de mostrar o sinal de Matriz, a palavra soletrada em Libras e a legenda em português, assim como a imagem, replicando o aprendizado no desafio proposto: fazer uma videoaula sobre Matriz de Surdo para Surdo, com base em um roteiro previamente elaborado. O estudo de Quadros e Schmiedt (2006) alerta sobre a importância de relacionar o sinal em Libras com a imagem e depois com a palavra em português.

Tendo em vista o resultado obtido, foi realizada a gravação do vídeo de acordo com os seguintes procedimentos: o pesquisador lia a frase proposta pelo participante no roteiro, que era traduzida pelo intérprete e que era copiada pelo participante, que treinava os sinais em Libras. Ao sentir-se preparado para a gravação, este sinalizava ao intérprete, que também operava o equipamento, que então começava a filmar, respeitando o tempo e o comando do participante. Concluída a gravação, esta foi encaminhada para edição e publicação na Plataforma Moodle, do Grupo de Trabalho (GT) de Materiais Adaptados do contexto da pesquisa, e disponibilizada como material didático para a aula de matemática e de programação. 
http://dx.doi.org/10.5902/1984686X39507

\section{Considerações finais}

Os resultados da análise parecem corroborar a premissa que deu suporte ao presente estudo: o sujeito Surdo tem capacidade para aprender conceitos complexos desde que respeitada sua especificidade linguística e cultural, porém alerta para a necessidade de ampliação do universo do estudo para que os resultados possam ser alargados.

Em relação à pergunta que guiou a pesquisa: Como ensinar conceitos complexos a estudantes Surdos para que tenham acesso ao conhecimento formal no contexto de formação profissional integrado ao ensino médio e igualdade de condições e oportunidades no mundo do trabalho? $\mathrm{O}$ estudo sugere que alguns procedimentos metodológicos de ensino sejam seguidos, tanto em contextos bilíngues como em nãobilíngues. São eles: i) identificar o nível de desenvolvimento real do estudante sobre o assunto a ser abordado (conforme preconizam VYGOTSKY, 1988; AUSUBEL, 2000 apud MOREIRA, 2010; FREIRE, 1996, entre outros), seja por meio de teste diagnóstico seja por meio de tarefa diagnóstica; ii) planejar o ensino a partir do nível identificado, visando avançar no desenvolvimento cognitivo do estudante (VYGOTSKY, 1988) de forma gradativa, calibrada e cíclica, porém diversificada; iii) respeitar as especificidades de aprender do estudante Surdo e sua cultura (conforme defendem os estudos de QUADROS; SCHMIEDT, 2006; SÁ, 2010; SACKS, 2010; SKLIAR, 2016, entre outros); iv) relacionar as atividades de aprendizagem à vida/ao mundo do trabalho (FREIRE, 1996), visando dar sentido ao ato de aprender e de ensinar; v) buscar relacionar simultaneamente a palavra escrita em português com o sinal em Libras e seu significado, pois assim o estudante terá mais possibilidade de ampliar o conhecimento propedêutico / específico juntamente com o português escrito e seu uso na/para a vida; vi) ressaltar as palavras-chave em negrito e/ou maiúscula nas atividades escritas em português, evidenciando o que é importante compreender para resolver o desafio proposto pelo professor; vii) usar materiais concretos, ferramentas e recursos digitais que oportunizem ao estudante aprender vendo e manipulando (REZENDE, 2017).

Contudo o estudo alerta sobre o tempo e esforço despendido para o planejamento, elaboração e adaptação de materiais especiais, sobre a necessidade de o trabalho docente ser desenvolvido em colaboração com profissionais de atendimento educacional especializado e intérprete de Libras, e sobre a necessidade de se ampliar o número de 
http://dx.doi.org/10.5902/1984686X39507

participantes em pesquisas futuras, visando trazer mais insights para a inclusão de estudantes Surdos em contextos educacionais não-bilíngues.

Por fim, o estudo leva a sugerir que as ações inclusivas desenhadas para este estudo, voltadas especificamente para o desenvolvimento cognitivo do estudante Surdo, podem ser replicadas para qualquer área do conhecimento e viabilizam não apenas a inclusão deste em espaços formais de educação, mas também promovem a conscientização de que o conhecimento é para todos ao longo da vida.

\section{Referências}

ARAÚJO, Ronaldo Marcos de Lima; FRIGOTTO, Gaudêncio. Práticas pedagógicas e ensino integrado. Revista Educação em Questão, Natal, v. 52, n. 38, p. 61-80, maio/ago. 2015.

BARDIN, L. Análise de conteúdo. Lisboa: Edições 70, 1977.

BOGDAN, Roberto C.; BIKLEN, Sari Knopp. Investigação qualitativa em educação: uma introdução à teoria e aos métodos. Porto, Portugal: Editora Porto, 1994.

BRASIL. Lei $\mathbf{1 0 . 4 3 6}$ de 24 de abril de 2002. Dispõe sobre a Língua Brasileira de Sinais Libras e dá outras providências. Brasília, 2002. Disponível em:

http://www.planalto.gov.br/ccivil_03/leis/2002//10436.htm Acesso em: 08 ago. 2019.

BRASIL. Decreto 5.154 de 23 de julho de 2004. Regulamenta o $\S 2^{\circ}$ do art. 36 e os arts. 39 a 41 da Lei $n^{\circ}$ 9.394, de 20 de dezembro de 1996, que estabelece as diretrizes e bases da educação nacional, e dá outras providências. Disponível em:

https://educacaoprofissional.seduc.ce.gov.br/images/decretos/Decreto_5154-2004.pdf Acesso em: 01 ago. 2019.

BRASIL. Decreto 5.626 de 22 de dezembro de 2005. Regulamenta a Lei $n_{\circ}$ 10.436, de 24 de abril de 2002, que dispõe sobre a Língua Brasileira de Sinais - Libras, e o art. 18 da Lei n. 10.098, de 19 de dezembro de 2000. Brasília, 2005. Disponível em: http://www.planalto.gov.br/ccivil_03/_Ato2004-2006/2005/Decreto/D5626.htm. Acesso em: 05 jan. 2020.

BRASIL. Saberes e práticas da inclusão: desenvolvendo competências para o atendimento às necessidades educacionais especiais de alunos surdos. 2. ed. SEESP/MEC. Brasília: MEC, Secretaria de Educação Especial, 2006.

BRASIL. Resolução no 6 de 20 de setembro de 2012. Define Diretrizes Curriculares Nacionais para a Educação Profissional Técnica de Nível Médio- Brasília: MEC/CNE/Câmara de Educação Básica, 2012. Disponível em:

https://moodle.ead.ifsc.edu.br/pluginfile.php/219691/mod_resource/content $/ 1 /$ Resolu\%C3\%A 7\%C3\%A30\%20CNE-CEB\%2006-2012\%20-\%20DCN\%20Cursos\%20T\%C3\%A9cnicos.pdf Acesso em: 23 jun. 2018. 
CIAVATTA, Maria. A formação integrada: a escola e o trabalho como lugares de memória e de identidade. In: FRIGOTTO, Gaudêncio; CIAVATTA, Maria. RAMOS, Marise (Orgs.). Ensino Médio Integrado: concepção e contradições. São Paulo: Cortez, 2005.

FIGUEIREDO, Saionara. Reflexões acerca de estudos sobre imagem e significação e sua relação com os sujeitos surdos usuários da língua brasileira de sinais. In: BÄR, Eliana; MASUTTI, Mara (Orgs.). Educação Bilíngue Libras Português: Pesquisa e fazer educativo. Florianópolis: IFSC, 2015.

FREIRE, Paulo. Pedagogia da Autonomia: Saberes necessários à prática educativa. São Paulo: Paz e Terra, 1996.

LACERDA, Cristina Broglia Feitosa de; SANTOS, Lara Ferreira dos; CAETANO, Juliana Fonseca. Estratégias Metodológicas para o Ensino de Alunos Surdos. In: LACERDA, Cristina Broglia Feitosa de; SANTOS, Lara Ferreira dos. (Orgs.). Tenho um aluno Surdo, e agora? Introdução à Libras e educação de surdos. São Carlos: EdUFSCar, 2014. p. 185-200.

LAKATOS, Eva Maria; MARCONI, Marina de Andrade. Fundamentos de metodologia científica. 5. ed. São Paulo: Atlas, 2003.

LIMA, Fernanda Bartoly Gonçalves de. A formação de professores nos institutos federais de educação, ciência e tecnologia: um estudo da concepção política. Natal: IFRN, 2014.

LIBÂNEO, José Carlos. Didática. 2. ed. São Paulo: Cortez, 2013.

MACHADO, Lucília. Ensino médio e técnico com currículos integrados: propostas de ação didática para uma relação não fantasiosa. In: MOLL, Jaqueline et al. Educação Profissional e Tecnológica no Brasil contemporâneo: desafios, tensões e possibilidades. Porto Alegre: Artmed, 2010. p. 80-95.

MOREIRA, Marco Antônio. O que é afinal aprendizagem significativa? Aula Inaugural do Programa de Pós-Graduação em Ensino de Ciências Naturais, Instituto de Física: Universidade Federal do Mato Grosso. Cuiabá, 2010. Disponível em: http://moreira.if.ufrgs.br/oqueeafinal.pdf. Acesso em: 15 jul. 2019.

OECHSLER, Vanessa. Comunicação Multimodal: produção de vídeos em aulas de Matemática. [S.I]: Universidade Estadual Paulista, Instituto de Geociências e Ciências Exatas. Rio Claro, 2018.

OLIVEIRA, Hagar de Lara Tiburcio de; SCHMITT, Rosiléia Serafim. A Inclusão na Educação de Jovens e Adultos. In: FRANÇA, Rodrigo Marcellino de. SOARES, Katia Vargas. (Orgs.). A educação especial como prática inclusiva: movimento da rede municipal de Gaspar. Prefeitura Municipal de Gaspar/SEMED. Blumenau: Furb, 2016. p. 97-102. Disponível em: http://static.fecam.com.br/uploads/878/arquivos/878051_Educacao_Especial.pdf. Acesso em: 16 jun. 2018.

OLIVEIRA, Marta Kohl de. Vygotsky: Aprendizado e Desenvolvimento um Processo SócioHistórico. São Paulo: Editora Scipione, 1997. 
PLATAFORMA NILO PEÇANHA. Rede Federal de Educação Profissional Científica e Tecnológica. SETEC/MEC. Disponível em: http://plataformanilopecanha.mec.gov.br/. Acesso em: 20 nov. 2017.

PRODANOV, Cleber Cristiano; FREITAS, Ernani Cesar de. Metodologia do trabalho científico [recurso eletrônico]: métodos e técnicas da pesquisa e do trabalho acadêmico. 2. ed. Novo Hamburgo: Feevale, 2013.

QUADROS, Ronice Müller de. Educação de Surdos: A aquisição da linguagem. Porto Alegre: Artmed, 1997.

QUADROS, Ronice Muller de; SCHMIEDT, Magali L. P. Ideias para ensinar português para alunos surdos. Brasília: MEC, SEESP, 2006.

RAMOS, Marise. Ensino médio integrado: ciência, trabalho e cultura na relação entre educação profissional e educação básica. In: MOLL, Jaqueline e colaboradores; Educação Profissional e Tecnológica no Brasil contemporâneo: desafios, tensões e possibilidades. Porto Alegre: Artmed, 2010. p. 42-57.

REZENDE, Dayselane Pimenta Lopes. Produto Educacional: Tarefas exploratório investigativas para o estudo de polígonos no $8^{\circ}$ ano do ensino fundamental. Programa de Mestrado Profissional em Educação Matemática. Juiz de Fora, MG, 2017.

SÁ, Nídia Regina Limeira de. Cultura, poder e educação de surdos. São Paulo: Paulinas, 2010.

SACKS, Oliver. Vendo vozes: uma viagem ao mundo dos surdos. São Paulo: Companhia das Letras, 2010.

SALLES, Heloísa Maria Moreira Lima; et al. Ensino de língua portuguesa para surdos: caminhos para a prática pedagógica. Brasília: MEC, SEESP, 2007.

SANTANA, Ana Paula. Surdez e linguagem: Aspectos e implicações neurolinguísticas. São Paulo: Plexus, 2007.

SIQUEIRA, Jonara Medeiros. Um estudo sobre a educação de Surdos e a TV INES. UFCG. III CINTEDI: Campina Grande, 2018. Disponível em: http://editorarealize.com.br/revistas/cintedi/trabalhos/TRABALHO_EV110_MD1_SA7_ID122_ 21082018160001.pdf Acesso em: 17 jul. 2019.

SKLIAR, Carlos. (Org.). A surdez: um olhar sobre as diferenças. 8. ed. Porto Alegre: Mediação, 2016.

VYGOTSKY, Lev Semenovich; LURIA, Alexander Romanovich; LEONTIEV, Alex. N. Linguagem, Desenvolvimento e Aprendizagem. Tradução Maria da Penha Villalobos. São Paulo: Ícone. Editora da Universidade de São Paulo, 1988.

VYGOTSKY, Lev Semyonovich. A formação social da mente. São Paulo: Martins Fontes, 1989. 
http://dx.doi.org/10.5902/1984686X39507

YIN, Robert K. Estudo de Caso: Planejamento e Métodos. 5.ed. Porto Alegre: Bookman, 2015.

\section{ZWAN, Liciara Daiane. Ambiente Virtual Inclusivo para o Ensino de Matemática para}

Alunos Surdos da Educação Básica. [S.I]: Universidade Regional Integrada do Alto Uruguai e das Missões. Campus de Santo Ângelo, 2016.

\section{Notas}

${ }^{1}$ Segundo o Decreto 5.626/05, considera-se pessoa surda aquela que, por ter perda auditiva, compreende e interage com o mundo por meio de experiências visuais, manifestando sua cultura principalmente pelo uso da Língua Brasileira de Sinais - LIBRAS. Em outras palavras, a falta de audição não é vista como deficiência, mas como diferença sociocultural pela Comunidade Surda. Por isso, os Estudos Surdos têm utilizado a expressão surdo com "S" maiúsculo, buscando representar a identidade dessa comunidade.

${ }^{2}$ Instituto Federal de Educação Ciência e Tecnologia de Santa Catarina.

${ }^{3}$ Surdez severa - perda auditiva de 71 a 90 Decibéis. A pessoa surda tem dificuldade de ouvir o som do telefone tocando, por exemplo. (BRASIL, 2006).

${ }^{4}$ Por L1 entendemos a primeira língua do participante: a Libras, no caso deste estudo.

${ }^{5}$ Por L2 entendemos a segunda língua do participante: o português escrito, no caso deste estudo.

${ }^{6}$ Educação bilíngue envolve aprendizagem em pelo menos duas línguas no contexto educacional. No caso de Surdos, geralmente considera-se a língua visoespacial como língua materna ou primeira língua e a língua portuguesa na modalidade escrita como segunda língua. (BRASIL, 2005; QUADROS, 2006).

7 Embora no Brasil a literatura apresente diferentes grafias para se referir ao autor russo Lev Semenovich Vygotsky, tais como Vigotski e Vygotsky, manteremos neste texto a grafia do original em russo.

${ }^{8} \mathrm{O}$ estudo foi aprovado pela Comissão de Ética em Pesquisa (CEP) da Universidade Federal de Santa Catarina (UFSC) sob o número 3.011.224.

${ }^{9} \mathrm{O}$ produto educacional, constituído pelos planos de aula aqui referenciados, estão postados no Portal EduCAPES com o título: Aprendendo para Ensinar Matrizes: atividades de ensino de estudante Surdo para estudante Surdo, e seu acesso é aberto.

10 Por limitação de espaço, serão apresentadas neste artigo apenas as ideias gerais dos planos de aula desenhados para o produto educacional.

\section{Correspondência}

Marimar da Silva - Instituto Federal de Santa Catarina, Campus Florianópolis Continente, Rua Quatorze de Julho, Estreito, Florianópolis, Santa Catarina, Brasil. CEP: 88075-010

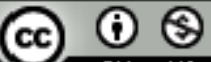

4.0 International (CC BY-NC 4.0) 